\title{
COMBINING URBAN METABOLISM METHODS AND SEMANTIC 3D CITY MODELS
}

\author{
I. Hijazi $^{12, *}$, V. Ebert ${ }^{1}$, A. Donaubauer ${ }^{1}$, T. H. Kolbe. ${ }^{1,}$ \\ ${ }^{1}$ Chair of Geoinformatics, Technical University of Munich, Arcisstr. 21, Munich, Germany - (ihab.hijazi, andreas.donaubauer, \\ thomas.kolbe)@tum.de \\ ${ }^{2}$ Urban Planning Engineering Department, An-Najah National University, Nablus, Palestine - (eehab@najah.edu)
}

\section{Commission VI, WG VI/4}

KEY WORDS: Stocks and Flows, Urban Metabolism, 3D City Model, CityGML, General Indicator Model GIM, Dynamizer, UtilityNetworkADE

\begin{abstract}
:
The last decade has witnessed increasing interest in the study of urban stocks and flows. This paper provides a literature review for different studies of urban stocks and flows. The review shows that urban stocks and flows studies can be categorized according to their output and spatial resolution: The first type of studies uses a lower scale of spatial resolution and focuses on the city as one unit. The second type of studies uses a higher spatial resolution to analyze stocks and flows of sub-areas of the city and is therefore able to produce maps to visualize their results. Both types of studies can either use recent data in a non-dynamic way, or use a time series of data, which allows for the investigation of the city's development over time. Information about input and output data per study was determined. The literature review also identifies problems associated with current studies, which are related to data availability and accuracy, assumptions, simplifications, and errors. The paper proposes that stocks and flows studies could benefit greatly from the linkage with a standardized semantic 3D city model, such as defined by the CityGML standard. Feedback on CityGML and its ADE
\end{abstract} capabilities to model urban metabolism is provided.

\section{INTRODUCTION}

With the growing world population and the increasing urbanization, cities have become a main initiator of ecological and environmental problems. Most of the problems in modern cities arise from a high per capita consumption of resources, which results in equally large amounts of waste and triggers problems like pollution of air, water, and soil, depletion of resources, or loss of green spaces. The impact of urban areas can not only be observed within the city's boundary, but it also effects the surrounding local, regional, and global environment (Environmental Problems, 2016). Therefore, there is a considerable need for concepts to support integrated policies and sustainable development.

One approach is the concept of urban metabolism, which compares urban areas to living organisms. It is used to quantify inputs, outputs and storage of energy, water, nutrients, materials and waste as well as people, land, capital and information (Kennedy et al. 2011, Schmitt 2015) and can therefore serve as a basis for sustainable urban design and policy analysis (Kennedy et al. 2011). Urban metabolism can either be implemented as static stock and flow analysis (e.g. material or energy flow analysis) or as a dynamic stocks and flows model (Schmitt 2015). Both stocks and flows approaches can help to break down the complexity of urban areas and support decisions concerning urban planning and design (Schmitt 2015). Some areas of application are the identification of main sources of greenhouse gas (GHG) emissions, calculation of the sustainability of a city according to certain indicators and determination of the potential for building material recycling. While stocks and flows models do not handle the spatial distribution of variables, Geographical Information Systems (GIS) can be used for spatio-temporal analysis, like visualization of population density per area or changes in land-use.

To overcome the shortcomings of the stocks and flows on the one hand and GIS on the other hand several authors (Neuwirth et al. 2015, Zhao and Coors 2012) have investigated the integration of GIS and stocks and flows models. However, semantic 3D city models as a new approach were not investigated yet.
An extension to GIS applications are specific 3D city models using the international standard CityGML. CityGML provides a representation of geometrical, topological and semantic properties of real life urban objects, like buildings, vegetation, water bodies and transportation facilities (Kolbe et al. 2005). With its ability to store various information, the model can serve as an information hub for other applications, such as stocks and flows models.

Combining the stocks and flows concept with a 3D city model can support urban planning by simulating complex urban relationships, while at the same time providing a standardized approach to extract and store data.

\section{REVIEW APPROACH}

Within the literature review for this paper, 18 studies were analyzed, which ranged from the years 2001 to 2016. The publications were studied in terms of their required input data, methodology, and resulting output. Based on this analysis, literature was classified into two groups, the first one included studies on city level and the second one included studies on subarea level (Table 1 and 2).

The first group calculated indicators for the whole city, which were further distinguished into elementary indicators (based on raw data) and complex indicators (based on elementary indicators). The studies belonging to this group did not consider the spatial course of flows within the city.

The second group calculated indicators for sub-areas of the city, which made it possible to represent flows between them. Most studies have been carried out in the area of transportation to visualize the flows of people between sub-areas of the city. Studies dealing with other urban flows between sub-areas were very scarce. This group therefore included also studies, which considered urban flows through time, which means that they compared the same area for different points in time and calculated the flows that occurred between those time points. The results of the second group, which were based mostly on elementary indicators, were represented using maps.

\footnotetext{
* Corresponding author
} 


\subsection{Summary of input and output data}

\section{Input data}

The input data was different for city level studies and sub-area level studies due to their different spatial resolution. City level studies were based on the city as a whole and calculated flows into and out of the city, which were sometimes grouped into broader material categories. They did not consider the spatial path of flows within the city, mostly because of the lack of data, since data was often only available at national level and the collection of more detailed information, for example on neighbourhood level, would have required considerable efforts. The input data for this type of studies included the volumes of flows beyond the area's boundary and between subsystems of the area.

\begin{tabular}{|c|c|c|}
\hline Study & Topic & Output Type \\
\hline $\begin{array}{l}\text { Baker, Hope et al. } \\
\text { (2001) }\end{array}$ & Nutrients & Elementary indicator \\
\hline Færge et al. (2001) & Nutrients & Elementary indicator \\
\hline Sörme et al. (2001) & Metal & Elementary indicator \\
\hline $\begin{array}{l}\text { Obernosterer and } \\
\text { Brunner (2001) }\end{array}$ & Metal & Elementary indicator \\
\hline Feng et al. (2013) & Carbon & Elementary indicator \\
\hline Chen and Chen (2012) & Carbon & Elementary indicator \\
\hline $\begin{array}{l}\text { Thériault and Laroche } \\
\text { (2009) }\end{array}$ & Water & Elementary indicator \\
\hline Zhang et al. (2009) & $\begin{array}{l}\text { Materials, } \\
\text { Energy }\end{array}$ & Complex indicator \\
\hline Huang and Hsu (2003) & $\begin{array}{l}\text { Materials, } \\
\text { Energy }\end{array}$ & Complex indicator \\
\hline Zhang and Yang (2007) & Materials & Complex indicator \\
\hline Schulz (2007) & Materials & Complex indicator \\
\hline Rosado et al. (2014) & Materials & Complex indicator \\
\hline
\end{tabular}

Table 1: Studies on city level

\begin{tabular}{|l|l|l|}
\hline Study & Topic & Output Type \\
\hline Keirstead et al. (2010) & Energy & Map \\
\hline Zhong et al. (2014) & Transportation & Map \\
\hline Liu et al. (2009) & Transportation & Map \\
\hline Hill and Lindner (2010) & Land use & Map \\
\hline $\begin{array}{l}\text { Deilmann } \\
\text { (2009) }\end{array}$ & Urban fabric & Map \\
\hline $\begin{array}{l}\text { Chen et al. (2016) } \\
\text { Construction } \\
\text { material }\end{array}$ & Map \\
\hline
\end{tabular}

Table 2: Studies on sub-area level

The aim of our investigation was determining which kind of flows were analyzed and which type of indicators were calculated. Even though elementary indicators are rather basic indicators quantifying material input and output of the system, they still required large amounts of input data. For some studies, transformation processes of the material had to be taken into account, which increased modeling complexity.

Elementary indicators can be used as input data for the calculation of complex indicators, which consider different flows and give a more holistic assessment of the performance of the city. Depending on the indicators the studies produced and the approach they chose, i.e. emergy (developed by Odum (1996), is the amount of energy that was consumed in direct and indirect transformations to make a product or service) analysis or material flow analysis, the studies required different types and amounts of input data. Some studies limited their calculation to a certain sector i.e. energy or water, which reduced the amount of required input data significantly while still providing meaningful indicators.

For sub-area level studies, similar input data was required, but on a higher spatial resolution (on neighbourhood or building level). Additionally, information on the spatial location of input data was needed, including the location of buildings, spatial layout of transportation networks, and spatial distribution of land uses.

Both types of studies can be used to assess the current situation, as well as to predict possible trends of future developments. When considering different scenarios, the boundary conditions or rules for those scenarios were required as additional input data. This included for example changes in policies, investment in infrastructure, or population growth.

Table 3 provides a general classification of required input data. The most commonly used input data belonged to the numeric type category and is needed for the calculation of elementary indicators, like volume of water consumption or number of inhabitants. The next category is relational input data, which specifies the relationship of different stocks or flows. The equations, which define those relationships, were for example required for the calculation of complex indicators. Relational input data was also required for the prediction of influences, for example to determine the effect of increased GDP on residential energy consumption. Spatial input data was required for sub-area level studies, for example the spatial layout of utility networks or distribution of land uses. The last type of input data is temporal data, which was required for the modeling of time series. It specifies the value of an indicator for certain points in time, for example the hourly energy consumption. Not all of the described data types were required for every study, in fact most studies used only two input data types, for example, for the calculation of complex indicators on city level, or to visualize spatial flows.

\begin{tabular}{|l|l|}
\hline $\begin{array}{l}\text { Type of } \\
\text { input data }\end{array}$ & Examples \\
\hline Numeric & $\begin{array}{l}\text { Volume of flows } \\
\text { Number of inhabitants } \\
\text { Material stock of products and buildings }\end{array}$ \\
\hline Relational & $\begin{array}{l}\text { Empirical equations for prediction of trends; } \\
\text { Equations for calculation of complex indicators }\end{array}$ \\
\hline Spatial & $\begin{array}{l}\text { Layout of utility networks } \\
\text { Distribution of land uses }\end{array}$ \\
\hline Temporal & Change of indicators over time \\
\hline \multicolumn{2}{|c|}{ Table 3: Overview of input data types }
\end{tabular}

\section{Output data}

There were two main types of output data resulting from the studies, the first one being numeric indicators and the second one being maps. Numeric indicators were furthermore classified as elementary indicators, which represented basic indicators derived from raw data (e.g. water consumption), or they were classified as complex indicators, which were calculated from several elementary indicators and provided a holistic assessment of the city's overall metabolism (e.g. eco-efficiency). Complex indicators were mostly calculated on city level, since they required data on different groups of the city (e.g. added value per economic sector, industrial energy consumption) and therefore could not be determined for individual neighborhoods or buildings. 
Elementary indicators as well as complex indicators can both be modeled for either one year to determine the current performance of the city and compare it to other cities, or for a longer time series to evaluate the city's development and future trends.

Studies on sub-area level often subdivided the city into cells to model the stocks and flows between different sub-areas. The stocks and flows were derived from elementary indicators, for example, the number of people using public transport, or energy consumption of buildings. The results were visualized in maps, which were not only used to analyze the current situation, but also to compare scenarios and predict the influence of different urban planning measures.

\begin{tabular}{|c|c|c|c|c|c|}
\hline Study & 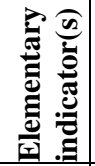 & 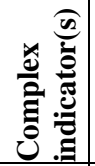 & 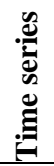 & 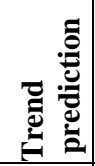 & $\sum^{\frac{0}{\pi}}$ \\
\hline Baker et al. (2001) & $\mathrm{x}$ & & & & \\
\hline Færge et al. (2001) & $\mathrm{x}$ & & & & \\
\hline Sörme et al. (2001) & $\mathrm{x}$ & & & & \\
\hline $\begin{array}{ll}\text { Obernosterer } & \text { and } \\
\text { Brunner (2001) } & \\
\end{array}$ & $\mathrm{x}$ & & & & \\
\hline Feng et al. (2013) & $\mathrm{x}$ & & $\mathrm{x}$ & $\mathrm{x}$ & \\
\hline Chen and Chen (2012) & $\mathrm{x}$ & & & & \\
\hline $\begin{array}{l}\text { Thériault and Laroche } \\
\text { (2009) }\end{array}$ & $\mathrm{x}$ & & & & \\
\hline Zhang et al. (2009) & & $\mathrm{x}$ & $\mathrm{x}$ & & \\
\hline Huang and Hsu (2003) & & $\mathrm{x}$ & $\mathrm{x}$ & & \\
\hline Zhang and Yang (2007) & & $\mathrm{x}$ & $\mathrm{x}$ & & \\
\hline Schulz (2007) & & $\mathrm{x}$ & $\mathrm{x}$ & & \\
\hline Rosado et al. (2014) & & $\mathrm{x}$ & $\mathrm{x}$ & $\mathrm{x}$ & \\
\hline Keirstead et al. (2010) & $\mathrm{x}$ & & & & $\mathrm{x}$ \\
\hline Zhong et al. (2014) & $\mathrm{x}$ & & & & $\mathrm{x}$ \\
\hline Liu et al. (2009) & $\mathrm{x}$ & & $\mathrm{x}$ & & $\mathrm{x}$ \\
\hline Hill and Lindner (2010) & $\mathrm{x}$ & & & $\mathrm{x}$ & $\mathrm{x}$ \\
\hline Deilmann (2009) & $\mathrm{x}$ & & & $\mathrm{x}$ & $\mathrm{x}$ \\
\hline Chen et al. (2016) & $\mathrm{x}$ & & $\mathrm{x}$ & & $\mathrm{x}$ \\
\hline
\end{tabular}

Table 4: Summary of output types per study

Table 4 gives an overview of the output type of each analyzed study. Most studies dealing with elementary indicators calculated them for a specific point in time to set up a material balance of average inflows and outflows of the study area, whereas studies dealing with complex indicators considered time series to assess the city's development over time. Studies on sub-area level, which produced maps based on elementary indicators, sometimes illustrated time series in maps or future trends as well.

\section{ADVANTAGES OF SEMANTIC 3D CITY MODELS}

As pointed out before most studies had to deal with problems related to data availability and accuracy. Data for stocks and flow studies is mostly only available on national or regional level and therefore needs to be scaled down to city level, which is associated with additional effort and a risk of overestimation (Sörme et al. 2001). Furthermore, assumptions and simplifications have to be made when data availability is not sufficient. In some cases, data from other literature has to be adopted, which bears a great risk of errors, because of the great range of possible values, depending on the applied methodology, or technological advancement. For studies on sub-area level data availability is an even bigger of a challenge, because they need considerably more detailed data.

Studies on city level as well as studies on sub-area level could benefit greatly from the use of a standardized semantic 3D city model through the following advantages:

1. Availability of data is improved

2. Data is provided on city object (e.g. building)

3. A common modeling framework is provided

4. Automatic derivation of data is possible

5. Information on data accuracy is provided

First of all, such a model would have the advantage of reducing the effort for data collection, which is one of the greatest challenges in modeling urban stocks and flows. Once data is stored in the model the information is readily available and can be extracted for a multitude of research questions, for example to calculate total stocks of metal bound in the city's infrastructure or to determine the main contributors of GHG emissions using methods such as presented by (Kaden et al. 2014).

Secondly, data would be stored on city object e.g. building level, which can be used easily for spatial studies, but at the same time can also be aggregated to quantify stocks and flows based on the whole city. Storing data on object level would also reduce data uncertainty resulting from downscaling.

Thirdly, the model would provide a standardized framework for modeling, which ensures data compatibility and comparability. Only this way cities could be compared on a common basis to identify potential for improvement.

A standardized way of modeling furthermore allows for the automatic derivation of data, which reduces the effort and time spent on data collection and also reduces human error. Moreover, data could be automatically passed on to other software to perform additional calculations.

Lastly, such a model could include information on data accuracy. Since accuracy could be stored for each object property the combination of different properties, for example for the calculation of complex indicators, overall accuracy could be determined easily.

Altogether, a standardized semantic 3D city model could serve as a holistic and uniform database of urban areas. Combining urban stocks and flows with a 3D city model could facilitate the study of urban metabolism and, thus, support sustainable urban planning and design.

\section{CITYGML AND RELEVANT APPLICATION DOMAIN EXTENSIONS}

\section{CityGML}

Standardized semantic 3D city models are, for example, provided through CityGML. It is an open data model and XML-based format for the storage and exchange of virtual 3D city models. Aside from the virtual 3D representation of city objects and their topological relationships, it includes semantic information to allow for thematic queries, analysis tasks and spatial data mining (Gröger et al. 2012). 
Since CityGML is a common semantic information model, it can be used for different application areas like urban planning, disaster management, environmental simulations, or navigation and tourism. CityGML is to be seen as a modeling framework with the aim of reaching a common definition of basic entities, attributes, and relations of a 3D city model. It is therefore possible to reuse data in different fields of interest and share data between different applications.

CityGML includes a spatial model, which defines the geometrical representation, an appearance model, defines textures and materials, and a thematic model, which represents the most important urban objects by a set of predefined object classes. The thematic modules which are important for this research paper include: Building, WaterBody, LandUse, CityObjectGroup, Generics. The Generics module can be used to extend predefined object classes by generic attributes or to extend thematic modules by generic objects, which allows to represent real world entities or properties of real world entities that are not represented by the predefined attributes or object classes.

Another way of adding additional objects and attributes to CityGML is possible through Application Domain Extensions (ADEs). This is especially useful for the modeling of more complex objects and relationships, in case the Generics module does not provide enough possibilities for their representation and allows to formally describe the extensions using UML/XMLSchema. Each ADE is defined in an extra schema and is furthermore related to a specific field of application (e.g. energy or noise). ADEs are used to add new object classes and relations between object classes and to add attributes to existing CityGML classes, which are not represented explicitly in the model. Several CityGML ADEs have been developed to date ${ }^{1}$. For the modeling of urban stocks and flows the Utility Network $\mathrm{ADE}$ and the Dynamizer ADE are of particular importance.

\section{Utility Network ADE}

The Utility Network ADE is used for the modeling of utility networks like, for example, water, electricity, sewage, or telecommunication networks. It consists of the NetworkCore model, the NetworkComponents model, and the NetworkProperties model (Becker et al. 2013).

The core model of the ADE has been refined by Kutzner and Kolbe (2016) to support additional modeling features. The core model is used for representing the topographical and topological aspects of the network in form of 3D city objects (e.g. pipes), as well as in form of a logical graph network consisting of nodes and edges. Kutzner and Kolbe (2016) also added the possibility to define supply areas, which is of special importance if no detailed information about the network is available. Representing flows in graph structure using UtilityNeworkADE is of great importance and required by different studies as the ones from Rosado et al. 2014 and Keirstead et al. 2010.

\section{Dynamizer ADE}

The Dynamizer ADE was developed to allow for the storage of dynamic properties and sensor observations within CityGML (Chaturvedi and Kolbe 2016). Each property of an object in CityGML can be linked to one or more dynamizers, in order to store time dependent variations of that property. This way, slow changes, like construction of buildings, as well as faster changes like energy demand or temperature can be modeled. The dynamic values can be represented in different ways:
- Tabulation of time/ value pairs

- Patterns of time/ value pairs

- Reference to an external file or database

- Retrieving of sensor observations

The ADE supports different data types which may change with time, for example numeric values, categories or spatial coordinates. It is therefore possible to model changes of different property types, including spatial, thematic and appearance properties. Time dependent values stored in the dynamizer feature override the static values of the CityGML object property, and if no dynamizer is connected to the object, the static values are not changed. Additionally, interpolation and aggregation of values is possible to generate missing values or to map multiple values to one point in time. The Dynamizer ADE is of particular importance to stocks and flows modeling, like the ones from Hung and Huso, 2013 and Schulz. 2017.

\section{General Indicator Model}

The General Indicator Model (GIM) is a modeling framework for the expression of elementary indicators, complex indicators and indexes (Elfouly et al. 2015). Its focus lies on modeling of the most decisive indicators, also called key performance indicators (KPI). Since many indicators can be connected to physical objects, the model provides an approach to link indicators to spatial features from various digital city and landscape models. Weaving classes are used to link indicators to different geospatial application models, like CityGML, INSPIRE, and Building Information Models (BIM). The model furthermore supports the derivation of domain specific indicator models, which include, for example, energy-related indicators or environment-related indicators. In this way, the GIM establishes a connection between the city modeler, who provides data of the digital city model, and the domain specialist, who provides the calculation of indicators and also allows for the automatic derivation of indicators based on data of the digital city model.

\section{CONNECTION OF CITYGML, UTILITY ADE, DYNAMIZER ADE, AND GIM WITH STOCKS AND FLOWS - MODELING APPROACH}

For connecting the Utility Network ADE, GIM, and Dynamizer ADE, a general workflow can be identified (Figure 1). First, the required input data has to be collected, whose amount and type depends on the use case. Next, the collected data has to be prepared for further usage. This again depends largely on the use case and the desired results. For the modelling of nutrient flows, for example, this includes the definition of subsystems and the type of product flows between them. In case of material flows, data preparation includes classification of buildings according to certain building types, from which the material stock can be determined. Another issue, which needs to be addressed during data preparation, is data compatibility. If input data is not available in a suitable spatial resolution, this data needs to be adjusted, so that it matches the required resolution for modeling. The next step is modeling the respective networks in CityGML using the Utility Network ADE. Then, indicators are calculated using the previously collected data and by formally modeling and linking them to their respective CityGML objects via the GIM framework. Finally, the Dynamizer ADE can be utilized to store time series of indicators, which can then be used to investigate the city's development. Some of the case studies analyzed previously were used to determine gaps and limitations of

\footnotetext{
1 An overview of CityGML ADEs can be found here: https://www.citygml.org/ade/
} 


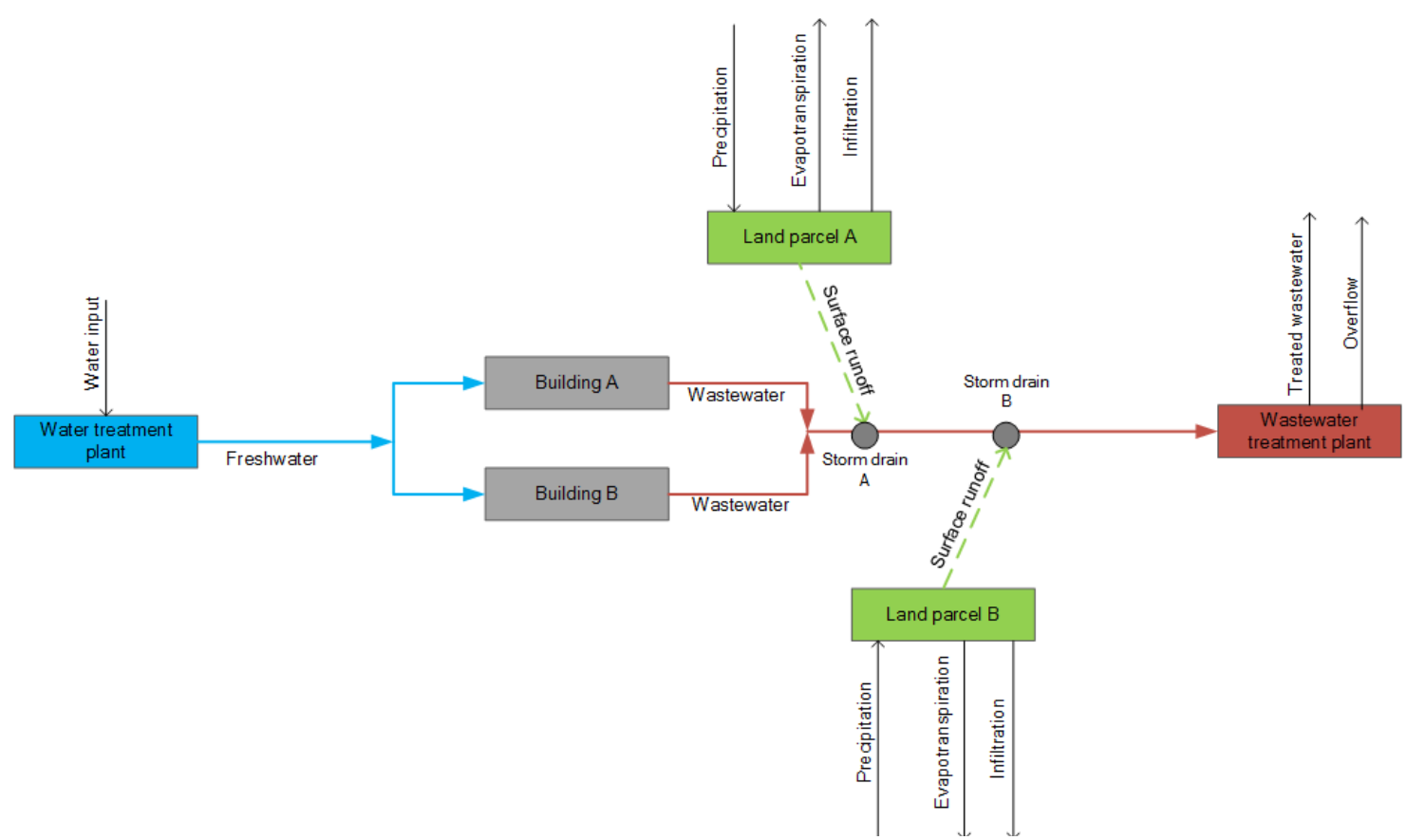

Figure 2 : Schematic layout of the water network (solid lines represent water flows in pipes and canals; dashed lines represent natural flows)

CityGML related to the modeling of stocks and flows. Four fundamental flows related to urban metabolism are: nutrients, energy, water, and materials. Therefore, studies focusing on one or several of those flows were analysed. Each analysis includes the possibilities of applying the Utility Network the ADE for modelling of flows, the General Indicator Model for the modelling of indicators and their connection to CityGML, as well as the Dynamizer ADE for modeling time series. A complete analysis of these studies are documented in (Ebert, 2017). The following provides a use case to demonstrate how the concept of CityGML can be applied to model physical and non-physical relationships between city objects. It also includes the calculation of indicators of building level, which can be aggregated to indictors on city level

\subsection{Description of the use case}

Good water management is an important topic for any city, since it results in reduced municipal costs for water services and protects the environment from excessive resource depletion and pollution. To implement a good water management program, a strategic plan has to be set up first, which is based on freshwater consumption, wastewater production, and storm water volume of the urban area. Goals of the strategic plan include the improvement of water efficiency, water conservation, and waterreduction, which is of especially great interest for cities dealing with water scarcity (Best Management Practice, 2018.). But also other cities can benefit from the cost reduction and improved environmental protection resulting from efficient water management.

\subsection{General data requirements}

To model the complete water stocks and flows, data on the spatial layout of the freshwater network, the wastewater network, and the storm water network was required (Figure 2). The modeling of water flows is especially diverse, since the complete network includes water flows constrained by man-made structures, as well as natural, diffuse water flows.
For the freshwater network, this required input data included the main distribution line, the lines connecting the main line to each house, as well as the location of the water source. This could be for example a freshwater treatment plant or a freshwater distribution station. For the wastewater network, required input data included the main wastewater line, the lines connecting the main line to each house, and the location of the wastewater treatment plant. Additionally, the location of each house was required to connect them to the freshwater and wastewater network.

The modeling of the storm water network depends on which type of network the study area uses. For a separate sewer system, where sanitary wastewater from houses and storm water from surface runoff is transported in separate pipes to different destinations, information about the spatial layout of the storm water sewer is required. In case of a combined sewer system,

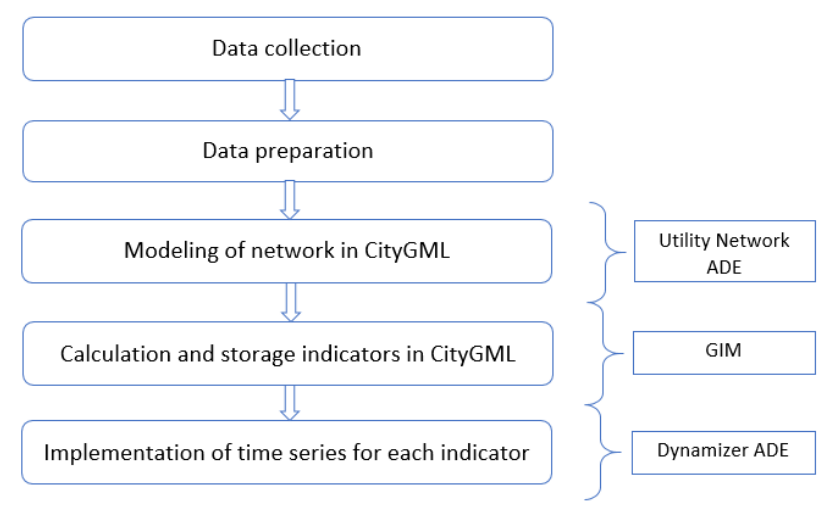

Figure 1: Workflow of modeling urban stocks and flows in CityGML

which was present in this use case, this information is not required. Instead, the location of storm drains needs to be known, which represent points where storm water enters the wastewater sewer. Actually, the spatial flow course of runoff would be required to model its way from the land parcel to the storm drain. 
In reality however, this is a highly complex natural process, which can hardly be predicted. In this use case, it was therefore represented by a logical link, which does not require information on the spatial course.

After modeling the water network, indicators can be calculated, which can then be used by city authorities to support sustainable urban planning. Since they are based on a spatial model, they can be calculated for the whole city, as well as for a selected area. Calculation of indicators required additional input data: the freshwater consumption and wastewater production per house, the impermeability and area of each land parcel, and the average precipitation. Indicators calculated in this implementation were used to set up a water balance, which defined total water input and total water output. The following indicators were calculated for the study area:

Freshwater consumption (total and per house) $\left[\mathrm{m}^{3} / \mathrm{y}\right]$

Wastewater production (total and per house) $\left[\mathrm{m}^{3} / \mathrm{y}\right]$ Precipitation volume (total and per land parcel) [ $\left.\mathrm{m}^{3} / \mathrm{y}\right]$

Evapotranspiration volume (total and per land parcel) [ $\left.\mathrm{m}^{3} / \mathrm{y}\right]$

Infiltration volume (total and per land parcel) $\left[\mathrm{m}^{3} / \mathrm{y}\right]$

Runoff volume (total and per land parcel) $\left[\mathrm{m}^{3} / \mathrm{y}\right]$

Inflow to wastewater treatment plant $\left[\mathrm{m}^{3} / \mathrm{y}\right]$

Treated wastewater $\left[\mathrm{m}^{3} / \mathrm{y}\right]$

Overflow $\left[\mathrm{m}^{3} / \mathrm{y}\right]$

\subsection{Modeling in CityGML}

The following section describes how input data, networks, and indicators related to water stocks and flows can be modelled in CityGML.

\section{Modelling of input}

The input data includes the topographical representation of city objects belonging to the water network, which can be modeled using the classes of the Utility Network ADE (Table 5). Houses can be modeled as ComplexFunctionalElement, since freshwater is transformed to wastewater within those elements. The attribute "class" could furthermore be used to specify the type of house (residential low-rise, industrial, etc.). Both the freshwater treatment plant as well as the wastewater treatment plant modify the incoming water flow and can therefore be modeled as ComplexFunctionalElement as well. There are two types of pipes for each network, one is the main line, which transports water from origin to destination, and the other type are connection lines, which connect the houses to the main line. For the freshwater network, both pipe types can be modeled as RoundPipe with different values for the attribute interiorDiameter. For the wastewater network, the connection pipe can be modeled as RoundPipe as well, whereas the main line would be modeled as ClosedCanal. Since in CityGML every network feature is connected to AbstractFeatureMaterial, the pipe types can be further distinguished by their assigned material.

The storm drains can be modeled as SimpleFunctionalElement, since they represent a structure, which allows storm water to enter the wastewater network. The only network member, which cannot be represented topographically using the Utility Network ADE is the logical link. This is because the Utility Network ADE was developed to describe physical connections, like pipes and cables. The logical link is necessary to connect features, which do not have a physical connection, but still transfer water flows to another network feature. Therefore, it can only be represented topologically using the AbstractLink feature. Depending on the features it connects, it can be either specialized into NetworkLink or InterFeatureLink.

The land parcels, which generate the surface runoff, can be modeled as LandUse features in CityGML, which include class, function, and usage attributes, as well as the geometry of the parcel. The "class" attribute can be used to distinguish if the surface is mostly built, or mostly natural, which determines the volume of runoff that is generated. For a more accurate analysis of runoff volumes the function and usage attributes could be used, which provide a more detailed distinction of different surfaces, including for example forest, grassland, and moor. To connect them to the storm network, they can be modeled as TerminalElement, since water enters the storm water network at this point in form of precipitation.

\section{Modeling of networks}

According to the Utility Network ADE, networks are defined as an aggregation of an arbitrary number of network features. The topographical representation of the freshwater network therefore includes the network features houses, freshwater treatment plant, and distribution elements in from of round pipes. The topological model includes nodes to represent the houses, the freshwater treatment plant, and the connection points between main line and connection lines, as well as InterFeatureLinks to connect all the nodes.

The same concept can be applied to the wastewater network, with the topographical representation including houses, the wastewater treatment plant, the storm drains, the main line and the connection lines. The topological model includes nodes to represent the features as well as InterFeatureLinks to connect them.

\begin{tabular}{|l|l|}
\hline Network member & $\begin{array}{l}\text { Corresponding Network } \\
\text { Utility ADE FeatureType }\end{array}$ \\
\hline House & ComplexFunctionalElement \\
\hline Freshwater treatment plant & ComplexFunctionalElement \\
\hline Wastewater treatment plant & ComplexFunctionalElement \\
\hline Main line of networks & RoundPipe or ClosedCanal \\
\hline Connection line of networks & RoundPipe \\
\hline Storm drain & SimpleFunctionalElement \\
\hline Surface runoff & AbstractLink \\
\hline Land parcel & TerminalElement \\
\hline
\end{tabular}

Table 4: Network members and their corresponding Network Utility ADE feature types

The storm water network includes the land parcels and flow of runoff to the storm drain. Since the spatial path of the runoff towards a storm drain is not constrained by man-made structure and therefore shows a highly complex pattern, a topographical representation is not suitable. Instead, the topological model can be used to represent the runoff as an InterFeatureLink between the land parcel and a storm drain.

To create a complete water network, the freshwater network and wastewater network need to be connected. This happens within the houses where the freshwater is transformed to wastewater. The houses therefore need to be split up further to include a feature representing freshwater input as well as a feature representing wastewater output. The connection between those two features can be represented by a topological link, namely the NetworkLink, which links two different networks. Since a network feature may consists of other network features, a house, which was defined as ComplexFunctionalElement, may contain 
other network features, like a freshwater input and a wastewater output. The freshwater input feature could be modeled as SimpleFunctionalElement to represent the structure that is attached to the freshwater connection line before drinking water is distributed within the house. The same applies to the wastewater output, which represents the structure before wastewater enters the wastewater connection line.

Altogether, the whole water network then consists of land parcels, which generate runoff, which is transported to storm drains, from where it is transported to the wastewater treatment plant. The freshwater treatment plant generates drinking water, which is transported to the freshwater input structure of houses and transformed to wastewater within the house. Wastewater leaves the house from the wastewater output structure, enters the wastewater network, and is finally treated in the wastewater treatment plant or discharged into the environment due to overflow.

Since all network features are derived from AbstractNetworkFeature, they inherit the attributes of function and usage. Those attributes can be used to define sources and sinks within the network by assigning the values feeding or draining. This way, the freshwater treatment plant can be defined as a water source, whereas the wastewater treatment plant can be defined as a sink.

\section{Modeling of indicators}

In CityGML, indicators can be stored as attributes for the city object they concern. Since suitable attributes do not exist yet in CityGML, they are stored as specializations of _genericAttribute. The volume of freshwater input and wastewater output is stored as two additional attributes for each house. Since the root class of the building module_AbstractBuilding possesses attributes to define class, function, and usage of a building, volume of freshwater consumption could be defined depending on one of those attributes. An office building, for example, would probably have a lower freshwater consumption than a hotel.

To calculate the runoff of a land parcel, the volume of precipitation, evapotranspiration and infiltration has to be known. Those values are stored as generic attributes for each land use object. The runoff is then calculated by precipitation minus evapotranspiration and infiltration.

To define indicators for a larger area, like for example a neighborhood, CityObjectGroup is used. This group includes the houses and land use parcels present within the desired area. Since CityObjectGroup is a specialization of _CityObject, it may the also be enhanced by generic attributes. Those attributes include freshwater consumption, wastewater production, precipitation volume, evapotranspiration volume, infiltration volume, and runoff volume, which are all calculated by summing up the respective attribute values of the city objects within the group.

To determine how much wastewater is discharged without treatment due to overflow, information about the total inflow and capacity of the wastewater treatment plant is required. Inflow, capacity, and overflow are stored again as generic attributes for the wastewater treatment plant. Inflow includes wastewater produced at buildings and runoff from land surfaces. Overflow is then calculated by inflow minus capacity. Treated wastewater

\section{REFERENCES}

Baker, L. A., Hope, D., Xu, Y., Edmonds, J., \& Lauver, L. 2001. Nitrogen balance for the Central Arizona-Phoenix (CAP) ecosystem. Ecosystems 4(6): pp. 582-602. can also be stored as an additional attribute, whose value is either equal to the total inflow, if the inflow is the same or less than the plant's capacity, or it is equal to the capacity, if inflow is higher than capacity then overflow is generated.

\section{CONCLUSIONS}

The study of urban metabolism provides information about various stocks and flows within the city, including consumption of resources and generation of waste, and can therefore be utilized to support sustainable urban planning.

To model urban stocks and flows in CityGML, the model needs to be able to store indicators on building level, sub-area level, and city level; it needs to be able to store time series of indicators; and it needs to be able to model the spatial course of flows within the city. To fulfil those requirements, CityGML was used together with the GIM for modeling indicators, the Utility Network ADE for modeling spatial flows, and the Dynamizer ADE to store time series.

By analyzing some case studies dealing with urban stocks and flows, the possibilities and limitations of modeling stocks and flows in CityGML have been determined. Aside from the ubiquitous challenge of data availability, the main limitations concerning the used data models were:

\section{CityGML and material flows}

Modeling the spatial course of flows using the Utility Network $\mathrm{ADE}$ is possible for many materials, but not for all. Since this $\mathrm{ADE}$ focuses on flows within utility networks, it is not well suited to represent natural, variable, or unconstrained flows. This applies in particular to surface runoff from land parcels to storm drains and the transport of commodities via road

\section{CityGML and indicators}

Based on the quantity or volume of flows, elementary indicators can be calculated. In CityGML, they can be easily added as additional attribute on building level and can then be aggregated for larger areas. Complex indicators on the other hand, which merge several material flows into one final indicator, cannot be stored at building level, since they are based on the whole city and often require the consideration of different urban sectors. CityGML provided nearly no suitable attributes for the calculation of indicators, therefore a large number of attributes needed to be added.

\section{CityGML and time}

The modeling of time series of indicators using the Dynamizer $\mathrm{ADE}$ is completely possible. Time series can be used as basis for the calculation of average values or to illustrate historic development.

A full implementation for a real world city district/block is needed in the future to demonstrate the conceptual approach

Becker, T., Nagel, C., \& Kolbe, T. H. 2013. Semantic 3D modeling of multi-utility networks in cities for analysis and 3D visualization. In: Progress and New Trends in $3 D$ Geoinformation Sciences pp. 41-62. Springer, Berlin, Heidelberg. 
Chaturvedi, K. and T. H. Kolbe 2016. Integrating Dynamic Data And Sensors With Semantic 3D City Models. ISPRS Ann. Photogramm. Remote Sens. Spatial Inf. Sci. IV-2/W1: 31-38.

Chen, S. and B. Chen 2012. Network environment perspective for urban metabolism and carbon emissions: a case study of Vienna, Austria. Environmental science \& technology 46(8): pp. 4498-4506.

Chen, C., Shi, F., Okuoka, K., \& Tanikawa, H. 2016. The Metabolism Analysis of Urban Building by 4d-GIS-A Useful Method for New-type Urbanization Planning in China. Universal Journal of Materials Science, 4(2), pp. 40-46.

Deilmann, C. 2009. Urban metabolism and the surface of the city. Guiding Principles for Spatial Development in Germany, Springer: pp. 1-16.

Ebert, V., 2017. CityGML and Urban Metabolism - Initial Investigations for Spatial Modeling of Stocks and Flows. Master thesis, Chair of Geoinformatics, Technical University of Munich, Munich, Germany.

Elfouly, M., Kutzner, T., \& Kolbe, T. H. 2015. General Indicator Modeling for Decision Support based on 3D city and landscape models using Model Driven Engineering. In Peer Reviewed Proceedings of Digital Landscape Architecture 2015 at Anhalt University of Applied Sciences.

Environmental Problems of Modern Cities, 2016. https://owlcation.com/stem/Environmental-problems-ofmodern-cities (1 July 2018)

Best Management Practice \#1: Water Management Planning., 2018., U.S. Department of Energy.

https://energy.gov/eere/femp/best-management-practice-1water-management-planning (1 July 2018)

Færge, J., Magid, J., \& de Vries, F. W. P. 2001. Urban nutrient balance for Bangkok. Ecological modelling, 139(1), pp. 63-74.

Feng, Y. Y., Chen, S. Q., \& Zhang, L. X. 2013. System dynamics modeling for urban energy consumption and $\mathrm{CO} 2$ emissions: A case study of Beijing, China. Ecological Modelling, 252, pp. 4452 .

Gröger, G., Kolbe, T. H., Nagel, C., \& Häfele, K. H. 2012. OGC city geography markup language (CityGML) encoding standard, Version 2.0, OGC doc no. 12-019. Open Geospatial Consortium.

Hill, A. and C. Lindner 2010. Land-use modelling to support strategic urban planning-the case of Dar es Salaam, Tanzania. 45th ISOCARP Congress.

Huang, S.-L. and W.-L. Hsu 2003. Materials flow analysis and emergy evaluation of Taipei's urban construction. Landscape and Urban Planning 63(2): pp. 61-74.

Kaden, R and Kolbe, T. H. 2014. Simulation-Based Total Energy Demand Estimation of Buildings using Semantic 3D City Models. International Journal of 3-D Information Modeling 3 (2), 2014, pp. 35-53.

Keirstead, J., Samsatli, N., \& Shah, N. 2010. SynCity: an integrated tool kit for urban energy systems modelling. Energy efficient cities: Assessment tools and benchmarking practices, pp. 21-42.
Kennedy, C., Pincetl, S., \& Bunje, P. 2011. The study of urban metabolism and its applications to urban planning and design. Environmental pollution, 159(8), pp. 1965-1973.

Kolbe, T. H., Gröger, G. and Plumer, L. 2005. CityGML: Interoperable access to 3D city models. Geo-information for disaster management, Springer: pp. 883-899.

Kutzner, T. and T. H. Kolbe 2016. Extending Semantic 3D City Models by Supply and Disposal Networks for Analysing the Urban Supply Situation. Dreiländertagung der DGPF, der OVG und der SGPF. Bern, Schweiz. 25.

Liu, L., Hou, A., Biderman, A., Ratti, C., \& Chen, J. 2009. Understanding individual and collective mobility patterns from smart card records: A case study in Shenzhen. In Intelligent Transportation Systems, 2009. ITSC'09. 12th International IEEE Conference On. IEEE.

Neuwirth, C., Peck, A., \& Simonović, S. P. 2015. Modeling structural change in spatial system dynamics: A Daisyworld example. Environmental Modelling \& Software, 65, pp. 30-40.

Obernosterer, R. and P. Brunner., 2001. Urban metal management the example of lead. Water, air and soil pollution: Focus 1(3-4): pp. 241-253.

Odum, Howard T. 1996. Environmental Accounting: Emergy and Environmental Decision Making. Wiley. p. 370. ISBN 9780-471-11442-0.

Rosado, L., et al. 2014. A material flow accounting case study of the Lisbon metropolitan area using the urban metabolism analyst model. Journal of Industrial Ecology 18(1): pp. 84-101.

Schmitt, G. N. 2015. "Information cities". Zürich, ETH Zürich, https://www.researchcollection.ethz.ch/handle/20.500.11850/99594

Schulz, N. B. 2007. The direct material inputs into Singapore's development. Journal of Industrial Ecology 11(2): pp. 117-131.

Sörme, L., Bergbäck, B., \& Lohm, U. 2001. Century perspective of heavy metal use in urban areas. A case study in Stockholm. Water, air and soil pollution: Focus, 1(3-4), pp. 197211.

Thériault, J. and A.-M. Laroche. 2009. "Evaluation of the urban hydrologic metabolism of the Greater Moncton region, New Brunswick." Canadian Water Resources Journal 34(3): pp. 255268.

Xu, Z., \& Coors, V. 2012. Combining system dynamics model, GIS and 3D visualization in sustainability assessment of urban residential development. Building and Environment, 47, pp. 272287.

Zhang, Y. and Z. Yang 2007. Eco-efficiency of urban material metabolism: a case study in Shenzhen, China. Acta Ecologica Sinica 27(8): pp. 3124-3131.

Zhang, Y., Yang, Z., \& Yu, X. 2009. Evaluation of urban metabolism based on emergy synthesis: A case study for Beijing (China). Ecological modelling, 220(13-14), pp. 1690-1696.

Zhong, C., Arisona, S. M., \& Schmitt, G. 2014. A Visual Analytics Framework for Large Transportation Datasets. 